\title{
Editorial
}

\section{What is the treatment of choice for Tl squamous cell carcinoma of the larynx?}

\author{
Alfio Ferlito, M.D., D.L.O., D.PATH., F.R.C.S. (ED.), F.R.C.S., F.A.S.C.P., F.R.C.S. (GlasG.), \\ M.C.A.P., F.R.C.S.I., F.A.C.S., M.R.C.PATH., F.H.K.A.M., PATRICK J. BrADLEY, M.B., B.CH., B.A.O., \\ D.C.H., M.B.A., F.R.C.S.I., F.R.C.S. (ED.), F.R.C.S.*, AlESSANDRA RINALDO, M.D.
}

The management of $\mathrm{Tl}$ laryngeal squamous cell carcinoma has a long and interesting history characterized by various phases and developments, and it remains a topic of widespread controversy in the world, largely because of the absence of a definitive prospective comparative analysis of treatment options.

Cancer of the larynx is a relatively rare disease, but it is the commonest head and neck cancer, excluding skin cancer. ${ }^{1}$ Traditionally, Tl squamous cell carcinoma of the larynx is treated with equal effectiveness by either conservative surgery or radiotherapy, as assessed by univariate and multivariate analysis. ${ }^{2}$

The preferred treatment modality at present is highly dependent on geography, with radiation tending to be the treatment of choice in Canada, northern Europe, Australasia and South Africa, whereas surgery is more usually used in southern Europe and in many centres of the United States. Since the 1970s, CO laser has been used to treat patients with T1A glottic carcinomas. ${ }^{3}$ In the past two decades, several reports by German, Belgian, Italian, Swiss, Spanish, Dutch, Japanese, Israeli, Indian and American colleagues have presented convincing evidence that endoscopic $\mathrm{CO}_{2}$ laser surgery can be considered a valid alternative for $\mathrm{Tl}$ glottic and supraglottic squamous cell carcinomas. ${ }^{4-20}$ The majority of patients neither require a tracheotomy nor the use of tube feeding. Conversely, as a result, open neck surgery for non-advanced laryngeal cancer has been recommended less.

Clinicians generally used the term 'early' cancer in an arbitrary way, and we take this opportunity to clarify the terminology in order to avoid any misinterpretation. Ferlito et al. ${ }^{21}$ considered 'early' laryngeal cancer to be confined to the lamina propria, but potentially to be capable of forming lymph node metastases when localized in the supraglottic area. The lesion does not invade muscle or cartilage. Therefore, 'early' cancer includes $\mathrm{Tl}$ lesions but excludes Tis, T2, T3 and T4 lesions. Microinvasive carcinoma and superficial extending carcinoma are subtypes of 'early' cancer. Early stages are not synonymous of 'early' cancer. To avoid an inadequate or overzealous approach to treatment and prognosis, a clinical diagnosis of 'early' invasive laryngeal cancer should be substantiated by careful microscopic pathological evaluation, which should exclude both carcinoma in situ and, particularly, deeply infiltrating carcinoma. ${ }^{21}$

In recent years endoscopic surgery and radiotherapy have undergone significant technical improvements, however, complications may result if either treatment methods are used. ${ }^{2,15}$ Some causes of treatment failure are not related to the treatment modality used. Residual cancer should be distinguished from local recurrence. ${ }^{22}$ Recurrent cancer is more often seen in patients who continue to smoke after treatment, in association with an underestimation of the initial tumour volume and its invasion and also in non-conventional squamous cell carcinoma. The clinical staging may not correlate with pathological staging, resulting in a $\mathrm{T} 4$ cancer of the glottis being included as 'early' cancer when pathological evaluation is not available to show microscopic invasion of adjacent cartilage or extralaryngeal soft tissues. ${ }^{21}$ This understaging is obviously a possibility with radiotherapy when only clinical staging is available. ${ }^{2}$ Most laryngologists have encountered patients in whom a carcinoma located in the vicinity of the anterior commissure was evaluated clinically and staged as a Tl lesion, but in whom subsequent pathological evaluation of a laryngectomy specimen revealed microscopic invasion of the adjacent cartilage or extralaryngeal soft tissues - a finding that forced reclassification of the carcinoma as a T4 lesion. ${ }^{21}$

The combination of cure with organ preservation and function is the most desirable outcome for patients with laryngeal cancer. Both radiotherapy and surgery, especially $\mathrm{CO}_{2}$ laser surgery, are equally effective at treating $\mathrm{Tl}$ glottic cancer, however, radiotherapy is often preferred over surgery because of the better functional results in terms of voice quality. 
In 2004, Jones et $a l^{2}$ demonstrated very clearly that speech and voice quality are significantly better in patients treated by irradiation than in those treated by surgery (endoscopic laser surgery and microscopic surgery). Several studies have been published indicating that the voice is near-normal after radiotherapy while poor voice quality is present after endoscopic laser treatment. ${ }^{23-25}$ In particular, Rydell et al. ${ }^{26}$ reported that the voice quality after laser treatment for T1A glottic cancer was inferior after treatment with full dose radiotherapy, as assessed both with acoustic and perceptual variables. Voice recordings prior to treatment, and at both 3 months and 2 years after completed treatment, were analyzed. Acoustic measures of shimmer, jitter, breathiness, harmonic-to-noise ratio and fundamental frequency average were calculated with the Soundscope programme. Two plain measures were also used: time required to read a running speech voice sample, and number of breaths. Perceptual voice analysis was performed blindly by two groups of listeners (experienced and naïve).

Considering the treatment costs, radiotherapy is marginally more expensive or similar to transoral endoscopic laser treatment but considerably cheaper than partial laryngeal surgery. ${ }^{2,27,28}$ The use of laser therapy does not preclude further treatments, if indicated, for cancer treatment (surgery or radiotherapy). Irradiation treatment failures can be salvaged by open partial laryngectomy. ${ }^{29}$

Although intensively debated, definitive radiotherapy remains a primary option for management of T1 glottis, considering long-term survival, local tumour control, quality of life, direct medical and nonmedical costs, indirect costs, and intangible costs. ${ }^{27}$ Endoscopic surgery with the $\mathrm{CO}_{2}$ laser can be considered a valid alternative but with a probably poorer voice quality.

Patients presenting with a $\mathrm{T} 1$ supraglottic cancer are relatively uncommon and have been encountered by accident during routine visits of patients being followed up for a different, treated primary head and neck cancer. The neck must be carefully examined because 'early' supraglottic cancers can be associated with metastases. 'Early' glottic cancer is synonymous with localized cancer; 'early' cancer of the supraglottis may invade lymphatic channels and metastasize to the neck and is considered a potentially disseminated type of disease. In fact, lymph node metastases have been reported in approximately 20 per cent of T1 supraglottic cancer. ${ }^{30}$ Considering that the risk of occult node disease is relatively high, even in the presence of a T1 supraglottic cancer, the nodes at risk (levels 2, 3 and 4) must be treated bilaterally with irradiation in conjunction with the primary malignancy.

Patients with T1 subglottic squamous cell carcinoma, although very rare in occurrence, have a high probability of cure with definitive radiation therapy alone and with preservation of normal voice, ${ }^{31}$ however, data supporting this approach are limited.

The recent published literature intimates that patients and physicians prefer to select a nonsurgical treatment for 'early' laryngeal cancer especially in the United States. ${ }^{32,33}$

\section{References}

1 Ferlito A. The natural history of early vocal cord cancer. Acta Otolaryngol 1995;115:345-7

2 Jones AS, Fish B, Fenton JE, Husband DJ. The treatment of early laryngeal cancers (T1-T2 N0): surgery or irradiation? Head Neck 2004;26:127-35

3 Strong MS, Jako GJ. Laser surgery in the larynx. Early clinical experience with continuous $\mathrm{CO}_{2}$ laser. Ann Otol 1972;81:791-8

4 Steiner W. Results of curative laser microsurgery of laryngeal carcinomas. Am J Otolaryngol 1993;14:116-21

5 Rudert HH, Werner JA. Endoscopic resections of glottic and supraglottic carcinomas with the $\mathrm{CO}_{2}$ laser. Eur Arch Otorhinolaryngol 1995;252:146-8

6 Shapshay SM, Hybels RL, Bohigian RK. Laser excision of early vocal cord carcinoma: indications, limitations, and precautions. Ann Otol Rhinol Laryngol 1990;99:46-50

7 Eckel HE, Thumfart W, Jungehulsing M, Sittel C, Stennert E. Transoral laser surgery for early glottic carcinoma. Eur Arch Otorhinolaryngol 2000;257:221-6

8 Peretti G, Piazza C, Balzanelli C, Mensi MC, Rossini M, Antonelli AR. Preoperative and postoperative voice in Tis-T1 glottic cancer treated by endoscopic cordectomy: an additional issue for patient counseling. Ann Otol Rhinol Laryngol 2003;112:759-63

9 Hirano M, Hirade $\mathrm{Y}$. $\mathrm{CO}_{2}$ laser for treating glottic carcinoma. Acta Otolaryngol Suppl 1988;458:154-7

10 Zeitels SM. Laser versus cold instruments for microlaryngoscopic surgery. Laryngoscope 1996;106:545-52

11 Remacle M, Lawson G. Transoral laser microsurgery is the recommended treatment for early glottic cancers. Acta Otorhinolaryngol Belg 1999;53:175-8

12 Gallo A, de Vincentiis M, Manciocco V, Simonelli M, Fiorella ML, Shah JP. CO laser cordectomy for early-stage glottic carcinoma: a long-term follow-up of 156 cases. Laryngoscope 2002;112:370-4

13 Moreau PR. Treatment of laryngeal carcinomas by laser endoscopic microsurgery. Laryngoscope 2000;110:1000-6

14 Tamura E, Kitahara S, Ogura M, Kohno N. Voice quality after laser surgery or radiotherapy for T1a glottic carcinoma. Laryngoscope 2003;113:910-4

15 Vilaseca-González I, Bernal-Sprekelsen M, BlauchAlejandro J-L, Moragas-Lluis M. Complications in transoral $\mathrm{CO}_{2}$ laser surgery for carcinoma of the larynx and hypopharynx. Head Neck 2003;25:382-8

16 Motta G, Esposito E, Cassiano B, Motta S. T1-T2-T3 glottic tumors: fifteen years experience with $\mathrm{CO}_{2}$ laser. Acta Otolaryngol Suppl 1997;527:155-9

17 Shvero J, Koren R, Zohar L, Hadar T, Marshak G, Gal R, et al. Laser surgery for the treatment of glottic carcinomas. Am J Otolaryngol 2003;24:28-33

18 Goor KM, Mahieu HF, Leemans CR, Peeters AJ, Langendijk JA, van Agthoven M. CO laser decortication: an efficient alternative to radiotherapy in the treatment of T1a carcinomas of the glottis. Ned Tijdschr Geneeskd 2003; 147:1177-81 [in Dutch]

19 Stoeckli SJ, Schnieper I, Huguenin P, Schmid S. Early glottic carcinoma: treatment according patient's preference? Head Neck 2003;25:1051-6

20 Pradhan SA, Pai PS, Neeli SI, D'Cruz AK. Transoral laser surgery for early glottic cancers. Arch Otolaryngol Head Neck Surg 2003;129:623-5

21 Ferlito A, Carbone A, Rinaldo A, DeSanto LW, D'Angelo L, Barnes L, et al. 'Early' cancer of the larynx: the concept as defined by clinicians, pathologists, and biologists. Ann Otol Rhinol Laryngol 1996;105:245-50

22 Goerres GW. Imaging literature and terminology: when is it residual cancer and when recurrence? Arch Otolaryngol Head Neck Surg 2004;130:120-1

23 McGuirt WF, Blalock D, Koufman JA, Feehs RS, Hilliard AJ, Greven K, et al. Comparative voice results after laser resection or irradiation of T1 vocal cord carcinoma. Arch Otolaryngol Head Neck Surg 1994;120:951-5 
24 Lehman JJ, Bless DM, Brandenburg JH. An objective assessment of voice production after radiation therapy for stage I squamous cell carcinoma of the glottis. Otolaryngol Head Neck Surg 1988;98:121-9

25 Schuller DE, Trudeau M, Bistline J, LaFace K. Evaluation of voice by patients and close relatives following different laryngeal cancer treatments. J Surg Oncol 1990;44:10-4

26 Rydell R, Schalen L, Fex S, Elner A. Voice evaluation before and after laser excision vs. radiotherapy of T1A glottic carcinoma. Acta Otolaryngol 1995;115:560-5

27 Foote RL, Buskirk SJ, Grado GL, Bonner JA. Has radiotherapy become too expensive to be considered a treatment option for early glottic cancer? Head Neck 1997; 19:692-700

28 Grégoire V, Hamoir M, Rosier JF, Counoy H, Eeckhoudt $\mathrm{L}$, Neymark $\mathrm{N}$, et al. Cost-minimization analysis of treatment options for T1N0 glottic squamous cell carcinoma: comparison between external radiotherapy, laser microsurgery and partial laryngectomy. Radiother Oncol 1999;53:1-13

29 Mendenhall WM, Werning JW, Hinerman RW, Amdur RJ, Villaret DB. Management of T1-T2 glottic carcinomas. Cancer 2004;100:1786-92

30 DeSanto LW. Cancer of the supraglottic larynx: a review of 260 patients. Otolaryngol Head Neck Surg 1985;93:705-11

31 Ferlito A, Rinaldo A. The pathology and management of subglottic cancer. Eur Arch Otorhinolaryngol 2000; 257:168-73
32 Shah JP, Karnell LH, Hoffman HT, Ariyan S, Brown GS, Fee WE, et al. Patterns of care for cancer of the larynx in the United States. Arch Otolaryngol Head Neck Surg 1997; 123:475-83

33 DiNardo LJ, Kaylie DM, Isaacson J. Current treatment practices for early laryngeal carcinoma. Otolaryngol Head Neck Surg 1999;120: 30-7

Address for correspondence:

Alfio Ferlito, M.D., D.L.O., D.Path., F.R.C.S. (Ed.), F.R.C.S., F.A.S.C.P., F.R.C.S. (Glasg.), M.C.A.P., F.R.C.S.I., F.A.C.S., M.R.C.Path., F.H.K.A.M.

Director of the Department of Surgical Sciences,

Professor and Chairman of the ENT Clinic

University of Udine,

Policlinico Universitario,

Piazzale S. Maria della Misericordia, 1-33100 Udine, Italy.

Fax: +390432 559339

E-mail: a.ferlito@uniud.it

Professor A. Ferlito takes responsibility for the integrity of the content of the paper.

Competing interests: None declared 